\title{
THE EFFECT OF EARLY INITIATION OF BREASTFEEDING ON POSTPARTUM HEMORRHAGE
}

\author{
Yulice Soraya, Meidona N. Milla, Naila Zulva \\ Faculty of Medicine, Universitas Islam Sultan Agung Semarang
}

\begin{abstract}
Background: Postpartum hemorrhage is a major problem that endangers maternal health. Its prevention can save mothers' life postnatal, through early initiation of breast-feeding. This study aimed to determine the effect of early initiation of breastfeeding on postpartum hemorrhage.

Subjects and Method:This was acohort studyconducted at Sultan Agung Islamic Hospital, Semarang, Central Java. A total of 60 postpartum mothers consisting of 30 early breastfeeding initiation and 30 without early breastfeeding initiation were selected for this study. The dependent variable was the amount of vaginal blood loss during the fourth stage of labor. The independent variable was early breastfeeding initiation. The data on the amount of blood loss were taken from the medical record. The other data were collected by questionnaire. The datawere analyzed by Mann Whitney.

Results: The amount of postpartum vaginal hemorrhage in the early initiation of breastfeeding group (Mean=148.88; $\mathrm{SD}=43.34 \mathrm{ml}$ ) was larger than the nonearly initiation of breastfeeding group (Mean $=323.67 ; \mathrm{SD}=99.50 \mathrm{ml}$ ), and it was statistically significant $(\mathrm{p}=0.001)$.

Conclusion:Early initiation of breastfeeding is effective to reduce postpartum vaginal hemorrhage.
\end{abstract}

Keywords: early initiation, breastfeeding, postpartum, vaginal hemorrhage.

\section{Correspondence:}

Yulice Soraya. Faculty of Medicine, Universitas Islam Sultan Agung Semarang, Central Java. Email: yulicesoraya@yahoo.com. Mobile: 082133001148 